\title{
Antihyperglycemic and anti-inflammatory effects of fermented food paste in high-fat diet and streptozotocin-challenged mice
}

This article was published in the following Dove Press journal:

Drug Design, Development and Therapy

\begin{abstract}
Noraisyah Zulkawi,' Kam
Heng Ng,' Nur Rizi Zamberi, 2,3

Swee Keong Yeap, ${ }^{4}$ Dilan A

Satharasinghe, ${ }^{5}$ Sheau Wei Tan, ${ }^{2}$

Wan Yong Ho, ${ }^{6}$ Nur Yuhasliza

Abd Rashid, ${ }^{3}$ Mohd Izwan Md

Lazim, ${ }^{3}$ Anisah Jamaluddin, ${ }^{3}$

Noorjahan Banu Alitheen, 2,7

Kamariah Long ${ }^{3}$

'Technical Research - Product

Development Department, Elken Global

Sdn. Bhd, Kuala Lumpur, Malaysia; ${ }^{2}$ Institute

of Bioscience, Universiti Putra Malaysia,

Serdang, Selangor, Malaysia; ${ }^{3}$ Malaysian

Agricultural Research and Development

Institute (MARDI), Serdang, Selangor,

Malaysia; ${ }^{4}$ China-ASEAN College of Marine

Sciences, Xiamen University Malaysia,

Sepang, Selangor, Malaysia; ${ }^{5}$ Department

of Basic Veterinary Sciences, Faculty of

Veterinary Medicine \& Animal Science,

University of Peradeniya, Peradeniya, Sri

Lanka; ${ }^{6}$ School of Biomedical Sciences, The

University of Nottingham Malaysia Campus,

Semenyih, Selangor, Malaysia; ${ }^{7}$ Department

of Cell and Molecular Biology, Faculty of

Biotechnology and Biomolecular Science,

Universiti Putra Malaysia, Serdang, Selangor,

Malaysia
\end{abstract}

Correspondence: Noorjahan Banu Alitheen Department of Cell and Molecular Biology, Faculty of Biotechnology and Biomolecular Science, Universiti Putra Malaysia, Serdang

43400 Selangor, Malaysia

Tel +6038946747l

Email noorjahan@upm.edu.my

Kamariah Long

Office of Deputy Director General (R\&D),

Malaysian Agricultural Research and

Development Institute, Serdang 43400,

Selangor, Malaysia

Tel +60389437732

Email amai@mardi.gov.my
Background: Fermented food has been widely consumed as health food to ameliorate or prevent several chronic diseases including diabetes. Xeniji ${ }^{\mathrm{TM}}$, a fermented food paste (FFP), has been previously reported with various bioactivities, which may be caused by the presence of several metabolites including polyphenolic acids, flavonoids, and vitamins. In this study, the anti-hyperglycemic and anti-inflammatory effects of FFP were assessed.

Methods: In this study, type 2 diabetes model mice were induced by streptozotocin and high-fat diet (HFD) and used to evaluate the antihyperglycemic and anti-inflammatory effects of FFP. Mice were fed with HFD and challenged with $30 \mathrm{mg} / \mathrm{kg}$ body weight (BW) of streptozotocin for 1 month followed by 6 weeks of supplementation with 0.1 and $1.0 \mathrm{~g} / \mathrm{kg}$ BW of FFP. Metformin was used as positive control treatment.

Results: Xeniji ${ }^{\mathrm{TM}}$-supplemented hyperglycemic mice were recorded with lower glucose level after 6 weeks of duration. This effect was contributed by the improvement of insulin sensitivity in the hyperglycemic mice indicated by the oral glucose tolerance test, insulin tolerance test, and end point insulin level. In addition, gene expression study has shown that the antihyperglycemic effect of FFP is related to the improvement of lipid and glucose metabolism in the mice. Furthermore, both 0.1 and $1 \mathrm{~g} / \mathrm{kg}$ BW of FFP was able to reduce hyperglycemia-related inflammation indicated by the reduction of proinflammatory cytokines, $N F-k B$ and $i N O S$ gene expression and nitric oxide level. Conclusion: FFP potentially demonstrated in vivo antihyperglycemic and anti-inflammatory effects on HFD and streptozotocin-induced diabetic mice.

Keywords: fermented foods, diabetic, inflammation, high-fat diet, lipid metabolism, glucose metabolism

\section{Introduction}

Diabetes is a global public health crisis contributed to by several factors including obesity, low physical activity, and intake of diet with excessive calories. ${ }^{1}$ Type 2 diabetes is characterized by increased level of blood glucose due to insulin resistance. ${ }^{2}$ Although several factors including obesity, low physical activity, genetics, and intake of diet with excessive calories contributed to the development of diabetes, ${ }^{1}$ obesity caused by intake of Western high-fat diet (HFD) was one of the top risk factors. ${ }^{2}$ To overcome the escalating diabetes health problem, several suggestions such as increasing physical activity and practicing healthy lifestyle or diet were proposed. ${ }^{3}$ It was hypothesized that traditional Asian diet including fermented food can help in preventing and delaying the progression of type 2 diabetes. ${ }^{4}$ Fermentation using lactic acid bacteria is a food processing method practiced since ancient time to improve flavor, aroma, and shelf life of fresh foods..$^{5}$ Among the commonly used lactic acid bacteria, Lactobacillus 
plantarum has been reported as the safest way to preserve food. ${ }^{5}$ Recent studies have shown that fermentation also helps to remove anti-nutritional factors ${ }^{5}$ and enhances bioactive metabolites such as polyphenols ${ }^{6}$ and isoflavone, ${ }^{7}$ which contributed to the improvement of bio-activities such as antibacterial, anti-inflammatory, anti-allergy, antioxidant, antihypertensive, and tyrosinase inhibitory effects. ${ }^{8}$ In addition, fermented food was also reported with antidiabetic effect. For example, fermented soybean improved glucose control in diabetic mice by improved sensitivity of insulin and glucose metabolism. ${ }^{7}$ The antidiabetic effect of fermented food may be contributed by the polyphenolic acid ${ }^{6}$ and even the lactic acid bacteria that were used for fermentation. ${ }^{9}$

Among the fermented food, fermented food paste (FFP) produced by fermenting fruits, vegetable, herbs, mushrooms, seaweed, and pulses using lactic acid bacteria is a convenient source of digestible nutrients in Japan. ${ }^{8}$ Xeniji ${ }^{\mathrm{TM}}$ is one of the commercial FFP that is available in Malaysia and Japan. A recent study has reported that FFP contained $\beta$-carotene, phytonadione, polyphenol, citric acid, and essential amino acids, which may have contributed to the antioxidant and immunostimulatory effect of $1 \mathrm{~g} / \mathrm{kg}$ body weight (BW) of raw FFP (dissolved in distilled water) on healthy BALB/c mice in vivo. ${ }^{10}$ In addition, vitamin and polyphenols in fermented food were also correlated to its antiinflammatory and inhibition of fat deposition effects. ${ }^{8,11}$ Presence of polyphenols particularly caffeolyquinic acid and sakuranetin in $1 \mathrm{~g} / \mathrm{kg} \mathrm{BW}$ of raw FFP (dissolved in distilled water) was also correlated with its in vivo hepato-recovery effect on ethanol-induced liver damage of BALB/c mice. ${ }^{12}$ Although FFP contained essential amino acids, vitamins, and polyphenolic acids ${ }^{10,13}$ and fermented food has been recorded to have potential antidiabetic effect, ${ }^{13}$ benefit of this FFP in regulating hyperglycemia particularly on type 2 diabetes is still unclear. Mice fed with HFD and challenged with streptozotocin were described as suitable model to resemble type 2 diabetes. ${ }^{13}$ Thus, this model was used in this study to evaluate the antihyperglycemia and anti-inflammatory effect of FFP.

\section{Methods}

\section{Preparation of FFP}

Commercially available FFP was provided by Elken Sdn Bhd, Malaysia. Preparation and ingredients of FFP were reported in the previous study. ${ }^{10}$ In brief, various food ingredients were batch fermented using commercial lactic acid bacteria (Table 1) for 3.5 years. ${ }^{10}$ Based on the previous study, FFP contained $\beta$-carotene, phytonadione, polyphenol, citric acid, and essential amino acids. ${ }^{10} \mathrm{FFP}$ used in this study was evaluated and standardized based on total phenolic content $(\sim 5 \mathrm{mg}$ GAE/g extract), citric acid ( $\sim 30 \mathrm{mg} / \mathrm{g}$ extract), aspartic acid

Table I Ingredients of FFP

\begin{tabular}{|c|c|c|}
\hline $\begin{array}{l}\text { Food } \\
\text { ingredients }\end{array}$ & Content & Concentration \\
\hline Sugar & Brown sugar, galacto-oligosaccharide (GOS), and oligosaccharide & $67.2 \%$ \\
\hline Fruits & $\begin{array}{l}\text { Prunus domestica L. (prune), Fragaria xananassa (strawberry), Malus domestica (apple), Vitis pione (grape), } \\
\text { Prunus persica (peach), Citrus unshiu (mandarin orange), mulberry, cherry blossom paste, Citrus junos (yuzu), } \\
\text { Diospyros kaki (persimmon), Actindia chinensis (kiwi), Fortunella japonica (kumquat), Citrus limon (lemon), } \\
\text { Vaccinium corymbosum (blueberry), Myrica rubra (artubus), Pyrus pyrifola (pear), Prunus mume (ume), Citrus iyo } \\
\text { (iyo-orange), Ficus carica (fig), Rubus buergeri (raspberry), and Rubus fruticosus (blackberry) }\end{array}$ & $18.0 \%$ \\
\hline $\begin{array}{l}\text { Vegetables } \\
\text { and wild herbs }\end{array}$ & $\begin{array}{l}\text { Angelica keiskei (folium) (Angelica keiskei leaf powder), Perilla frutescens (perilla), Cucurbita maxima (pumpkin), } \\
\text { Raphanus sativus (Japanese radish), Spinacia oleracea (spinach), Daucus carota var. Sativus (carrot), Brassica } \\
\text { oleracea, acephala (kale), Hordeum vulgare L. (barley grass), Corchorus olitorius (Jew's mallow), Lycopersicone } \\
\text { sculentum (tomato), Cucumis sativus (cucumber), Plantago asiatica (plantain), Sasa veitchii (stripped bamboo), } \\
\text { Equisetum arvense (field horsetail), Eriobotrya japonica (loquat leaf), Brassia oleracea var. Capitata (cabbage), } \\
\text { Salanum melongena (eggplant), Apium graveolens var. Dulce (celery), Capsicum annuum (sweet pepper), } \\
\text { Mormodica charantia (bitter melon), Brassica rapa chinensis (bok choi), Nelumbo nucifera (Radix) (lotus root), } \\
\text { Curcuma longa (turmeric), Brassica oleracea var. italica (broccoli), Zingiber officinale (ginger), Petroselinum } \\
\text { crispum cv (parsley), Asparagus officinalis var. Altilis (asparagus), and Oentanthes tolonifera (Japanese parsley) }\end{array}$ & $7.4 \%$ \\
\hline Mushrooms & $\begin{array}{l}\text { Ganoderma lucidum (reishi), Lentinula edodes (shiitake mushroom), Auricularia polytricha (Jew's ear), Grifola } \\
\text { frondosa (maitake mushroom) }\end{array}$ & $1.3 \%$ \\
\hline Seaweed & $\begin{array}{l}\text { Ascophyllum nodosum (kelp), Laminaria japonica Areschoug (kombu), Undaria pinnatifida suringer (wakame), } \\
\text { Fucuse vanescens (fucus), Sargassum fusiformesetchell (hijiki) }\end{array}$ & $1.6 \%$ \\
\hline $\begin{array}{l}\text { Pulses and } \\
\text { cereals }\end{array}$ & Glycine max (soybean), Theobroma cacao (cocoa), Zea mays L. (sweet corn), Oryza sativa (rice) & $4.4 \%$ \\
\hline $\begin{array}{l}\text { Lactic acid } \\
\text { bacteria } \\
\text { species }\end{array}$ & $\begin{array}{l}\text { Lactobacillus brevis, Lactobacillus casei, Lactobacillus curvatus, Lactobacillus paracasei, Lactobacillus pentosus, } \\
\text { Lactobacillus plantarum, Lactococcus lactis, Leuconostoc mesenteroides, Pediococcus acidilactici, Pediococcus } \\
\text { pentosaceus }\end{array}$ & $0.1 \%$ \\
\hline
\end{tabular}

Note: Reprinted from Zulkawi N, Ng KH, Zamberi R, et al. In vitro characterization and in vivo toxicity, antioxidant and immunomouldatory effect of fermented foods; Xeniji $^{\text {TM }}$. BMC Complement Altern Med. 20I7; 17:344. ${ }^{10}$ 
( $\sim 30 \mathrm{mg} / 100 \mathrm{~g}$ extract), and $\beta$-carotene $(\sim 5 \mathrm{mg} / \mathrm{g}$ extract $)$, which was similar to the our previous report. ${ }^{10}$ In this study, FFP was freshly prepared daily by dissolving in distilled water at the evaluated concentration prior to the supplementation.

\section{Animals and treatment}

Male mice ( $n=45,6$ weeks old) were purchased from animal house, Institute of Bioscience, Universiti Putra Malaysia (UPM). This study was approved by Institutional Animal Care and Use Committee, UPM (R045/2016). All animal experiments were carried out in accordance with the Malaysia Animals Act 1953 (Revised 2006) under Malaysian Veterinary Council for animal experiments. The animals were acclimatized for 2 weeks before starting the experiment. All mice were housed under standard condition at $22^{\circ} \mathrm{C}, 12$ hours of day/dark light cycles, humidity $\sim 70 \%$, and fed with distilled waterand standardmousepellets 702 (Gold Coin Holding, Selangor, Malaysia) ad libitum.

The mice were randomly divided into nine groups as stated below. Group 1 was the normal healthy mice that were fed with standard mouse pellets 702 (Cold Coin Holding,) throughout the experimental period. Mice from groups 2-5 were fed with HFD D12492 (Research Diet, Inc, New Brunswick, NJ, USA) ad libitum for 12 weeks. Major components of the standard diet and HFD are listed in Table $2 .{ }^{14}$ In addition, mice from groups 2-5 were injected with streptozotocin (35 mg/kg) (Sigma-Aldrich Co., St Louis, MO, USA) intraperitoneally on week $8 .{ }^{15}$ When the fasting glucose was $>270 \mathrm{mg} / \mathrm{dL}$ at week 12, mice from groups 3-5 were orally fed with metformin (CCM Pharmaceuticals Sdn Bhd, Selangor, Malaysia) or FFP using oral gavage for 6 weeks as stated below. Previous studies ${ }^{10,12}$ have shown that 0.1 and $1.0 \mathrm{~g} / \mathrm{kg}$ body weight (BW) of FFP enhanced the antioxidant effects in healthy and ethanol-induced liver damaged BALB/c mice. Thus, these concentrations were used in this study.

- Group 1, normal healthy $(n=5)$ : standard diet + normal saline buffer (Sigma-Aldrich Co.) only

- Group 2, untreated diabetic $(n=5)$ : HFD + streptozotocin challenged + distilled water

Table 2 Major components of the standard diet and high-fat diet

\begin{tabular}{lll}
\hline Content & $\begin{array}{l}\text { Standard pellet (g\%) } \\
\text { (Gold Coin, Malaysia) }\end{array}$ & $\begin{array}{l}\text { D I 2492 (g\%) } \\
\text { (Research Diet, USA) }\end{array}$ \\
\hline Protein & 22.0 & 26.2 \\
Fiber & 5.0 & 6.0 \\
Carbohydrate & 49.0 & 26.3 \\
Fat & 3.0 & 34.9 \\
Others & 21.0 & 6.6 \\
Total kcal/g & 3.8 & 5.2 \\
\hline
\end{tabular}

Note: Reprinted from Beh BK, Mohamad NE, Yeap SK, et al. Anti-obesity and anti-inflammatory effects of synthetic acetic acid vinegar and Nipa vinegar on high fat-diet-induced obese mice. Sci Rep. 2017;7:6664. ${ }^{14}$
- Group 3, metformin diabetic ( $\mathrm{n}=5)$ : HFD + streptozotocin challenged $+0.3 \mathrm{~g} / \mathrm{kg} \mathrm{BW}$ metformin

- Group 4, FFP0.1 diabetic (n=5): HFD + streptozotocin challenged $+0.1 \mathrm{~g} / \mathrm{kg}$ BW of FFP

- Group 5, FFP1.0 diabetic (n=5): HFD + streptozotocin challenged $+1.0 \mathrm{~g} / \mathrm{kg}$ BW of FFP

During the experimental period, fasting blood glucose level and food intake were measured weekly. Calorie intake per mouse was calculated based on the calorie/g for the standard diet and HFD (Table 2). At the end of the 18 weeks of experimental period, all mice were anesthetized with isoflurane (Sigma-Aldrich Co.) and euthanized by cervical dislocation. Liver, gonadal fat pads, and serum were collected and subjected to the following assays.

\section{Oral glucose tolerance test (OGTT)}

On week 17, all mice that fasted overnight were orally fed with $2.5 \mathrm{~g} / \mathrm{kg}$ BW of glucose (Sigma-Aldrich Co.). Subsequently, blood glucose level of the mice collected from tail vein was measured at 30, 60, 90, 120, and 180 minutes using OneTouch glucose meter (LifeScan, Inc, Chesterbrook, PA, USA).

\section{Insulin tolerance test (ITT)}

One week before the end of the experiment, all mice that fasted 6 hours were injected with $1 \mathrm{IU} / \mathrm{kg}$ BW of insulin intraperitoneal injection (CCM Pharmaceuticals Sdn Bhd). Subsequently, blood glucose level of the mice was measured for 30, 60, 90, 120, and 180 minutes using OneTouch glucose meter.

\section{Serum liver markers, insulin, and leptin}

Serum was collected for quantification of the following enzyme markers (aspartate aminotransferase [AST], alanine aminotransferase [ALT], alkaline phosphatase [ALP], and creatinine) and lipid profile (total cholesterol and triglyceride [TG]). The assays were performed in a biochemical analyzer (Hitachi 902 Automatic Analyzer; Hitachi Ltd., Tokyo, Japan) with adapted reagents from Hoffman-La Roche Ltd. (Basel, Switzerland). In addition, insulin and leptin levels in the serum were also determined using insulin and leptin ELISA kit (R\&D Systems, Inc., Minneapolis, $\mathrm{MN}, \mathrm{USA})$.

\section{Differential gene expression using real- time quantitative PCR (RT-qPCR)}

Expressions of inducible nitric oxide synthase (iNOS), nuclear factor kappa light chain enhancer of activated B cells (NF-kB), carnitine palmitoyl transferase I (CPTla), glucokinase, glucose-6-phosphate dehydrogenase (G6PD), phosphofructokinase and 6-phosphogluconate dehydrogenase in 
Table 3 Primer sequence of target genes for RT-qPCR assay

\begin{tabular}{|c|c|c|}
\hline Organ & Genes & Sequence $\left(5^{\prime}->3^{\prime}\right)$ \\
\hline \multirow{16}{*}{$\begin{array}{l}\text { Gonadal fat } \\
\text { pad }\end{array}$} & $A D$ & F: TCAGGAAGAGGAGGAGGA \\
\hline & & R: TCAGGAAGCACATCATACG \\
\hline & Glut I & F: GCAGTTCGGCTATAACAC \\
\hline & & TGG \\
\hline & & R: GCGGTGGTTCCATGTTTGA \\
\hline & & TTG \\
\hline & Glut4 & F: CTGCTTCTGGCTCTCACA \\
\hline & & R: AGGACATTGGACGCTCTC \\
\hline & Glut8 & F: CCCTTCGTGACTGGCTTTG \\
\hline & & R: TGGGTAGGCGATTTCCGA \\
\hline & & GAT \\
\hline & Insulin receptor (IR) & F: CGATGGCTTCTCAGACGTG \\
\hline & & R: CAGCCCGCTTGTTGATGTTG \\
\hline & SREBP & F: TCATCAACAACCAAGACAGT \\
\hline & & R: CCAGAGAAGCAGAAGAG \\
\hline & & AAG \\
\hline \multirow[t]{22}{*}{ Liver } & CPTIa & F: TGGCATCATCACTGGTG \\
\hline & & TGTT \\
\hline & & R: GTCTAGGGTCCGATTGATCT \\
\hline & & TTG \\
\hline & G6PD & F: CACAGTGGACGACATCCG \\
\hline & & AAA \\
\hline & & R: GCAGGGCATTCATGTGGCT \\
\hline & Glucokinase & F: AGGAGGCCAGTGTAAAGA \\
\hline & & TGT \\
\hline & & R: CTCCCAGGTCTAAGGAGAG \\
\hline & & AAA \\
\hline & Phosphofructokinase & F: TGCAGCCTACAATCTGC \\
\hline & & $\mathrm{TCC}$ \\
\hline & & R: GTCAAGTGTGCGTAGTT \\
\hline & & CTGA \\
\hline & 6-Phosphogluconate & F: CCTCGACTCTGCTTCGT \\
\hline & dehydrogenase & CTG \\
\hline & & R:AAGATCGCCTTGATGTGGGG \\
\hline & iNOS & F: GCACCGAGATTGGAGTTC \\
\hline & & R: TAGTTACACCGACACGAG \\
\hline & $N F-k B$ & F: CATTCTGACCTTGCCTATCT \\
\hline & & R: TCTTACCTGTCTTGTCGTC \\
\hline \multirow{3}{*}{$\begin{array}{l}\text { Housekeeping } \\
\text { gene }\end{array}$} & $\beta$-Actin & F: TCCTTCCTGGGCATGGAG \\
\hline & & R: AGGAGGAGCAATGATCTTGA \\
\hline & & TCTT \\
\hline
\end{tabular}

liver and adiponectin, glucose transporter 1 (Glut1), glucose transporter (Glut4), glucose transporter (Glut8), insulin receptor, and $S R E B P 1$ in gonadal fat pads were quantified. $\beta$-Actin was used as housekeeping gene. Primers for the evaluated targets and housekeeping genes are listed in Table 3. Livers and gonadal fat pads were stored in RNAlater solution (Thermo Fisher Scientific, Waltham, MA, USA) to preserve the RNA. The RNA was then extracted using an RNeasy Mini Kit (Qiagen NV, Venlo, the Netherlands). Total RNA $(1 \mu \mathrm{g})$ was reverse-transcribed to first-strand cDNA using NEXscript cDNA synthesis kit (NEX Diagnostics, Seoul, Korea) according to the manufacturer's protocols. The RNA and cDNA were aliquoted into five tubes and stored at $-80^{\circ} \mathrm{C}$.
RT-qPCR was performed with NEX proq PCR Evagreen Master Mix (NEX Diagnostics) using Eco Real Time PCR system (Illumina, San Diego, CA, USA) with the following steps: $95^{\circ} \mathrm{C}$ for 2 minutes, 40 cycles of $95^{\circ} \mathrm{C}$ for 10 seconds, $60^{\circ} \mathrm{C}$ for 45 seconds, and acquisition of fluorescent signal. Specificity and efficiency of primers were confirmed by RTqPCR melt curve and standard curve analysis. Non-template controls were used to confirm specificity. All samples were measured in triplicate. The expression levels of the target genes in all samples were normalized using the three housekeeping genes and further compared with those in the untreated control group by the Eco 48 software (Illumina). All the results were expressed as normalized fold changes compared with the untreated diabetic group.

\section{Glycogen and nitric oxide (NO) quantification}

Liver was excised from each mouse, washed with ice-cold phosphate-buffered saline (PBS; $137 \mathrm{mM} \mathrm{NaCl}, 2.7 \mathrm{mM} \mathrm{KCl}$, $10 \mathrm{mM} \mathrm{Na}_{2} \mathrm{HPO}_{4}, 2 \mathrm{mM} \mathrm{KH} \mathrm{PO}_{4}, \mathrm{pH}$ 7.4; Sigma-Aldrich $\mathrm{Co}$.), and weighted. One part of the liver was mashed using a $0.2 \mu \mathrm{m}$ cell strainer and syringe rubber plunger in cold PBS, to obtain a liver homogenate. The liver homogenate was used to determine the levels of glycogen and NO by using ELISA kit (Sigma-Aldrich Co.) and Griess assay (Thermo Fisher Scientific), respectively.

\section{Serum adipokine quantification}

Serum collected for the biomarkers evaluation was also subjected to interleukin-1 $\beta$ (IL-1 $\beta$ ) and tumor necrosis factor- $\alpha$ (TNF- $\alpha$ ) quantification using ELISA kits (R\&D Systems).

\section{Statistical analysis}

Mean and standard deviation from five mice per group were calculated by using Excel. Significant difference $(p<0.05)$ between the untreated diabetic mice with other groups for all experiments was tested using one-way analysis of variance followed by post hoc Duncan analysis using SPSS version 20 (IBM Corporation, Armonk, NY, USA).

\section{Results}

After 12 weeks of incubation, HFD streptozotocin-challenged diabetic mice were observed with three times higher fasting blood glucose compared with normal healthy mice $(p<0.05)$. For the following 6 weeks, untreated diabetic mice were recorded with further increase of fasting glucose to $\sim 300 \mathrm{mg} / \mathrm{dL}$ while normal healthy mice maintained the fasting blood glucose below $100 \mathrm{mg} / \mathrm{dL}(p<0.05)$. Metformintreated mice maintained lower fasting blood glucose than the 
untreated diabetic mice throughout the 6-week study period $(p<0.05)$. Moreover, FFP diet-supplemented mice also had reduced fasting blood glucose compared with untreated diabetic mice. After 3 weeks of FFP supplementation, FFP1.0 showed better effect than FFP0.1 in reducing the fasting blood glucose $(p<0.05)$ (Figure 1A).

\section{ITT and OGTT}

ITTs (Figure 1B) and OGTT (Figure 1C) were performed to measure insulin sensitivity and glucose tolerance. Compared with the untreated diabetic mice that had impaired glucose tolerance, metformin-treated and FFP diet-supplemented mice were observed with improved glucose metabolism and insulin sensitivity in the OGTT and ITT. When the two evaluated concentrations of FFP were compared, FFP1.0 was observed with faster reduction of glucose level and was able to maintain low blood glucose level even after 2.5 hours of insulin injection than in FFP0.1 supplemented mice.

\section{Food and calorie intake per mouse}

Overall, diabetic mice were recorded with significantly $(p<0.05)$ higher food/calorie intake than normal healthy

A
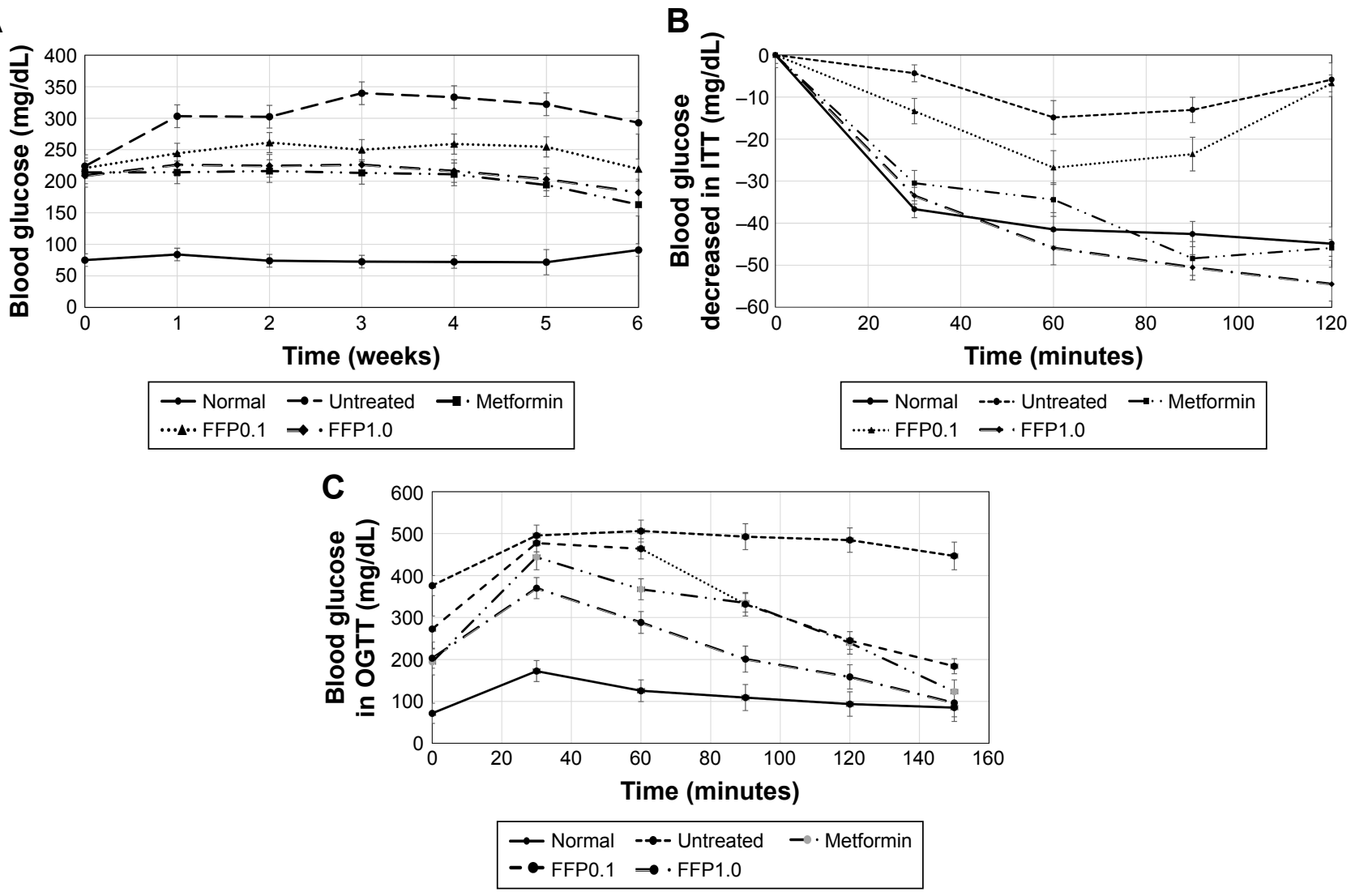

Figure I (A) Blood glucose level of normal, untreated, metformin-treated, and FFP-supplemented diabetic mice for the 6 weeks period. (B) Insulin tolerance and (C) oral glucose tolerance of normal, untreated, metformin-treated, and FFP-supplemented diabetic mice after 5 weeks of treatment. Note: FFPO.I and FFPI.0 indicate 0.1 and $1.0 \mathrm{~g}$, respectively, of FFP per kg of body weight.

Abbreviations: FFP, fermented food paste; ITT, insulin tolerance test; OGTT, oral glucose tolerance test.

mice (Figure 2A and B). Within the first 5 weeks of treatment, no significant difference was observed for food/calorie intake among all groups of diabetic mice. On the other hand, significantly lower level of food/calorie intake was observed in diabetic mice treated with metformin or supplemented with FFP1.0 after 6 weeks of duration. (Figure 2A and B).

\section{Serum insulin and leptin levels}

The effect of FFP, particularly at $1 \mathrm{~g} / \mathrm{kg} \mathrm{BW}$, in sensitizing the insulin was further supported with the reduction of fasting serum insulin and serum leptin levels (Table 4). Untreated diabetic mice were recorded with higher levels of serum insulin and serum leptin. On the other hand, metformin treatment and FFP1.0 diet supplementation significantly $(p<0.05)$ reduced the serum insulin and serum leptin levels compared with the untreated mice. FFP0.1 only significantly reduced the serum insulin level compared with the untreated mice.

\section{Serum lipid and liver enzyme profiles}

Untreated diabetic mice were recorded with higher levels of serum lipid (cholesterol and TG) and liver enzyme (AST, 

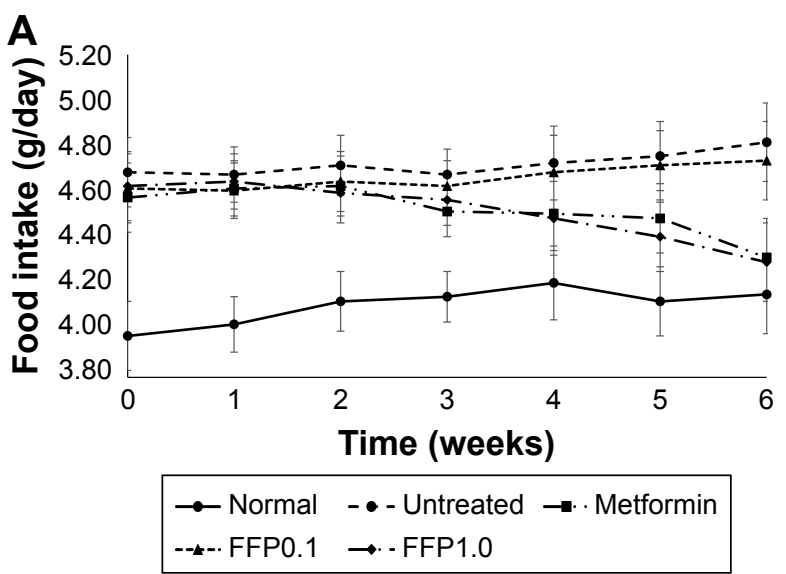

B

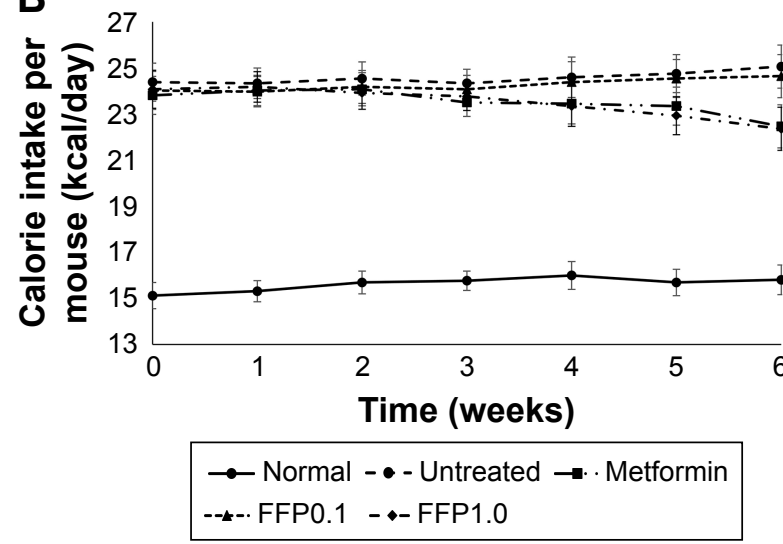

Figure 2 (A) Food (g/day) and (B) calorie intake per mice (kcal/day) of normal, untreated, metformin-treated, and FFP-supplemented diabetic mice for the 6 weeks period. Note: FFPO.I and FFPI.0 indicate 0.1 and $1.0 \mathrm{~g}$, respectively, of FFP per $\mathrm{kg}$ of body weight.

Abbreviation: FFP, fermented food paste.

ALT, and ALP) profiles. Metformin-treated diabetic mice were also recorded with significant $(p<0.05)$ lower level of serum lipid and liver enzyme profiles compared with untreated mice (Table 5). FFP0.1 diet-supplemented mice were recorded with significantly $(p<0.05)$ lower level of only serum TG, ALT, and ALP levels. In addition, FFP1.0 was also observed with significantly $(p<0.05)$ lower level of serum lipid and liver enzyme profiles compared with the untreated diabetic mice. Ten times higher supplementation of FFP on diabetic mice significantly $(p<0.05)$ further reduced the serum cholesterol, TG, ALP, and AST levels (Table 5).

\section{Liver glycogen level}

Untreated diabetic mice were recorded with 4.5-fold lower liver glycogen level compared to the normal healthy mice. Metformin, FFP1.0, and FFP0.1 were able to increase liver glycogen level by 3.00-, 2.15-, and 3.57-fold, respectively, compared with the untreated diabetic mice after 6 weeks of duration (Figure 3).

Table 4 Serum insulin and leptin, of normal, untreated diabetic, metformin-treated diabetic and fermented food pastesupplemented diabetic mice after 6 weeks of duration

\begin{tabular}{lll}
\hline Grouping & $\begin{array}{l}\text { Serum insulin } \\
(\mathbf{n g} / \mathrm{mL})\end{array}$ & $\begin{array}{l}\text { Serum leptin } \\
(\mathbf{n g} / \mathrm{mL})\end{array}$ \\
\hline Normal & $1.68 \pm 0.12^{\mathrm{d}}$ & $3.29 \pm 0.2 \mathrm{I}^{\mathrm{c}}$ \\
Untreated & $2.97 \pm 0.1 \mathrm{I}^{\mathrm{a}}$ & $7.36 \pm 0.25^{\mathrm{a}}$ \\
Metformin & $1.89 \pm 0.09^{\mathrm{c}}$ & $5.77 \pm 0.3 \mathrm{I}^{\mathrm{b}}$ \\
FFPO.I & $2.34 \pm 0.10^{\mathrm{b}}$ & $7.14 \pm 0.25^{\mathrm{a}}$ \\
FFPI.0 & $1.82 \pm 0.13^{\mathrm{c}}$ & $5.21 \pm 0.27^{\mathrm{b}}$ \\
\hline
\end{tabular}

Note: Different superscript letters indicate a significant difference compared with the untreated diabetic group, $p<0.05$.

\section{Expression of glucose metabolism, insulin signaling, and adipogenesis-related genes}

To understand how FFP regulates the glucose metabolism and insulin signaling pathway in the diabetic mice, expression of several genes that related to these pathways was observed by RT-qPCR. In the liver tissue, the expression of $G 6 P D$, glucokinase, phosphofructokinase, and 6-phosphogluconate dehydrogenase genes was found to be increased in the liver tissue of metformin-treated and FFP1.0 diet-supplemented diabetic mice (Figure 4). Moreover, expression of insulin signaling pathway-related genes, that is, Glut1, Glut4, Glut8, adiponectin, and insulin receptor genes were also ameliorated by the metformin treatment and FFP1.0 diet supplementation in the fat pad of the diabetic mice (Figure 5). In terms of adipogenesis-related genes, metformin treatment and FFP1.0 diet supplementation were able to ameliorate the expression of CPTla gene in liver (Figure 4) while the expression of SREBP1 gene in the fat pad was suppressed (Figure 6). When FFP1.0 and FFP0.1 diet supplementations were compared, 10 times higher dosage of FFP showed significantly $(p<0.05)$ additional benefit in ameliorating the expression of these evaluated genes in liver and fat pad.

\section{Serum IL-I $\beta$ and TNF- $\alpha$ adipokine levels}

Untreated diabetic mice were observed with highest serum IL-1 $\beta$ and TNF- $\alpha$ levels. On the other hand, metformin, FFP1.0, and FFP0.1 similarly helped to reduce the levels of IL- $1 \beta$ and TNF- $\alpha$ proinflammatory adipokines compared with the untreated diabetic mice. Both metformin treatment and FFP supplementation have even helped to reduce the level of serum IL-1 $\beta$ near to the level of normal healthy mice (Figure 5). 
Table 5 Serum lipid (cholesterol and TG) and liver enzymes (ALT, ALP, and AST) profiles of normal, untreated diabetic, metformintreated diabetic and FFP-supplemented diabetic mice after 6 weeks of duration

\begin{tabular}{llllll}
\hline & $\begin{array}{l}\text { Cholesterol } \\
(\mathbf{m m o l} / \mathbf{L})\end{array}$ & TG $(\mathbf{m m o l} / \mathbf{L})$ & ALT (U/L) & ALP (U/L) & AST (U/L) \\
\hline Normal & $2.52 \pm 0.08^{\mathrm{d}}$ & $1.35 \pm 0.06^{\mathrm{d}}$ & $69.30 \pm 8.68^{\mathrm{c}}$ & $49.33 \pm 1.41^{\mathrm{d}}$ & $167.66 \pm 18.92^{\mathrm{e}}$ \\
Untreated & $5.28 \pm 0.74^{\mathrm{b}}$ & $4.83 \pm 0.02^{\mathrm{a}}$ & $175.30 \pm 7.78^{\mathrm{a}}$ & $126.67 \pm 8.18^{\mathrm{a}}$ & $337.18 \pm 18.80^{\mathrm{a}}$ \\
Metformin & $4.59 \pm 0.03^{\mathrm{c}}$ & $2.76 \pm 0.04^{\mathrm{b}}$ & $81.25 \pm 4.95^{\mathrm{b}}$ & $88.00 \pm 4.14^{\mathrm{b}}$ & $253.76 \pm 15.22^{\mathrm{b}, \mathrm{c}}$ \\
FFP0.I & $5.74 \pm 0.32^{\mathrm{a}}$ & $1.92 \pm 0.01^{\mathrm{c}}$ & $73.25 \pm 5.44^{\mathrm{b}, \mathrm{c}}$ & $73.33 \pm 3.94^{\mathrm{c}}$ & $299.76 \pm 17.57^{\mathrm{a}, \mathrm{b}}$ \\
FFPI.0 & $4.77 \pm 0.29^{\mathrm{c}}$ & $1.20 \pm 0.06^{\mathrm{d}}$ & $70.35 \pm 3.80^{\mathrm{c}}$ & $56.00 \pm 5.66^{\mathrm{d}}$ & $213.50 \pm 14.00^{\mathrm{d}}$ \\
\hline
\end{tabular}

Notes: Different superscript letters indicate a significant difference compared with the untreated diabetic group, $p<0.05$. FFP0.I and FFPI.0 indicate 0.1 and I.0 g, respectively, of FFP per $\mathrm{kg}$ of body weight.

Abbreviations: ALP, alkaline phosphatase; ALT, alanine aminotransferase; AST, aspartate aminotransferase; FFP, fermented food paste; TG, triglyceride.

\section{Gene expression of NF-kB and iNOS in the liver}

FFP1.0 diet supplementation showed the highest suppression on the expression of proinflammatory related genes $i N O S$ and $N F-k B$ in the liver compared with the untreated diabetic mice. On the other hand, metformin treatment and FFP0.1 diet supplementation showed lower degree (but significant, $p<0.05$ ) of $i N O S$ and $N F-k B$ expression in the liver compared with the diabetic mice (Figure 7A).

\section{NO level in the liver}

Untreated diabetic mice were recorded with 2.9-fold higher liver NO level compared with the normal healthy mice. Metformin and FFP 1.0 were able to reduce $\sim 55 \%$ of the liver $\mathrm{NO}$ level in the diabetic mice after 6 weeks of duration. On the other hand, FFP0.1 reduced only $13 \%$ of the liver NO level compared with the diabetic mice (Figure 7B).

\section{Discussion}

Fermented food including FFP has been widely consumed as health supplements. ${ }^{8}$ However, health benefits of different

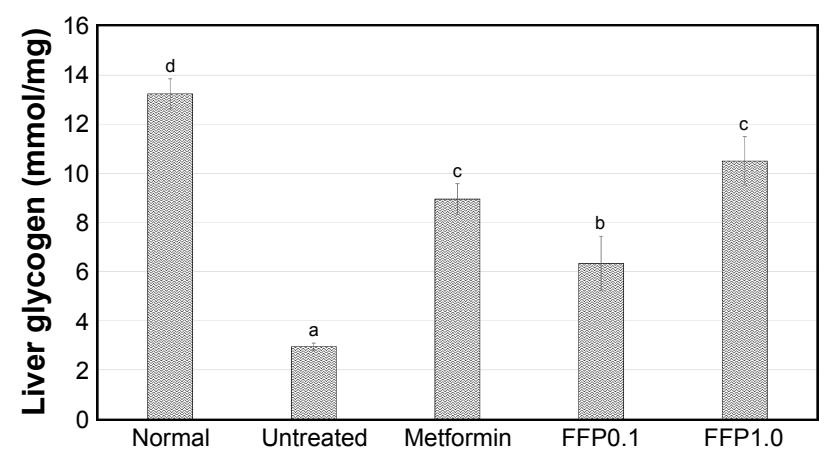

Figure 3 Liver glycogen level of normal, untreated, metformin-treated, and FFPsupplemented diabetic mice. Different superscript letters indicate a significant difference compared with the untreated diabetic group, $p<0.05$.

Note: FFPO.I and FFPI.0 indicate 0.1 and $1.0 \mathrm{~g}$, respectively, of FFP per $\mathrm{kg}$ of body weight.

Abbreviation: FFP, fermented food paste. types of fermented food can be varied contributed by the different source of food and strains of microbes used for the fermentation. ${ }^{16}$ Thus, it is important to evaluate the efficacy of fermented food to correlate with its health claim. In this study, the antihyperglycemic and anti-inflammatory effects of FFP were evaluated on the HFD + streptozotocin challenged diabetic mice. Previous study has shown that HFD-fed mice with streptozotocin impaired glucose tolerance as a result of the loss of early phase insulin secretion and subsequently caused insulin resistance. ${ }^{15}$ In this study, mice fed with HFD and single dose of streptozotocin were found to develop hyperglycemia after 12 weeks of observation. In this study, the untreated diabetic mice were observed with pathological condition of type 2 diabetes such as hyperglycemia, insulin resistant, depletion of liver glycogen, deposition of fat, and secretion of various adipokines such as TNF- $\alpha$ and leptin. ${ }^{17}$

Like metformin, FFP possessed antihyperglycemic effect after 6 weeks of diet supplementation. Reduction of blood glucose level by FFP was contributed by improved insulin sensitivity and glucose metabolism, which were indicated by the OGTT and ITT. Improved oral glucose tolerance value indicates enhanced adipose and liver sensitivity to insulin. ${ }^{18,19}$ Improvement of insulin resistance by FFP was supported by the upregulation of three different glucose transporters (Glut1, Glut4, and Glut8) and insulin receptor in the adipose tissue. Upregulation of glucose transporter gene expression also gives the clue that insulin sensitization by FFP diet supplement may achieve through increasing the translocation and glucose uptake in the diabetic mice. ${ }^{20}$ FFP diet supplement was also observed to have higher level of liver glycogen. Glycogen is the primary intracellular storable form of glucose converted by insulin in liver via activation of glycogen synthesis. ${ }^{19}$ Thus, enhancement of glycogen synthesis in the liver was also observed, indicating the improvement of hepatic insulin sensitivity in the type 2 diabetes. ${ }^{19}$ Furthermore, insulin was also involved in the activation of liver metabolism 


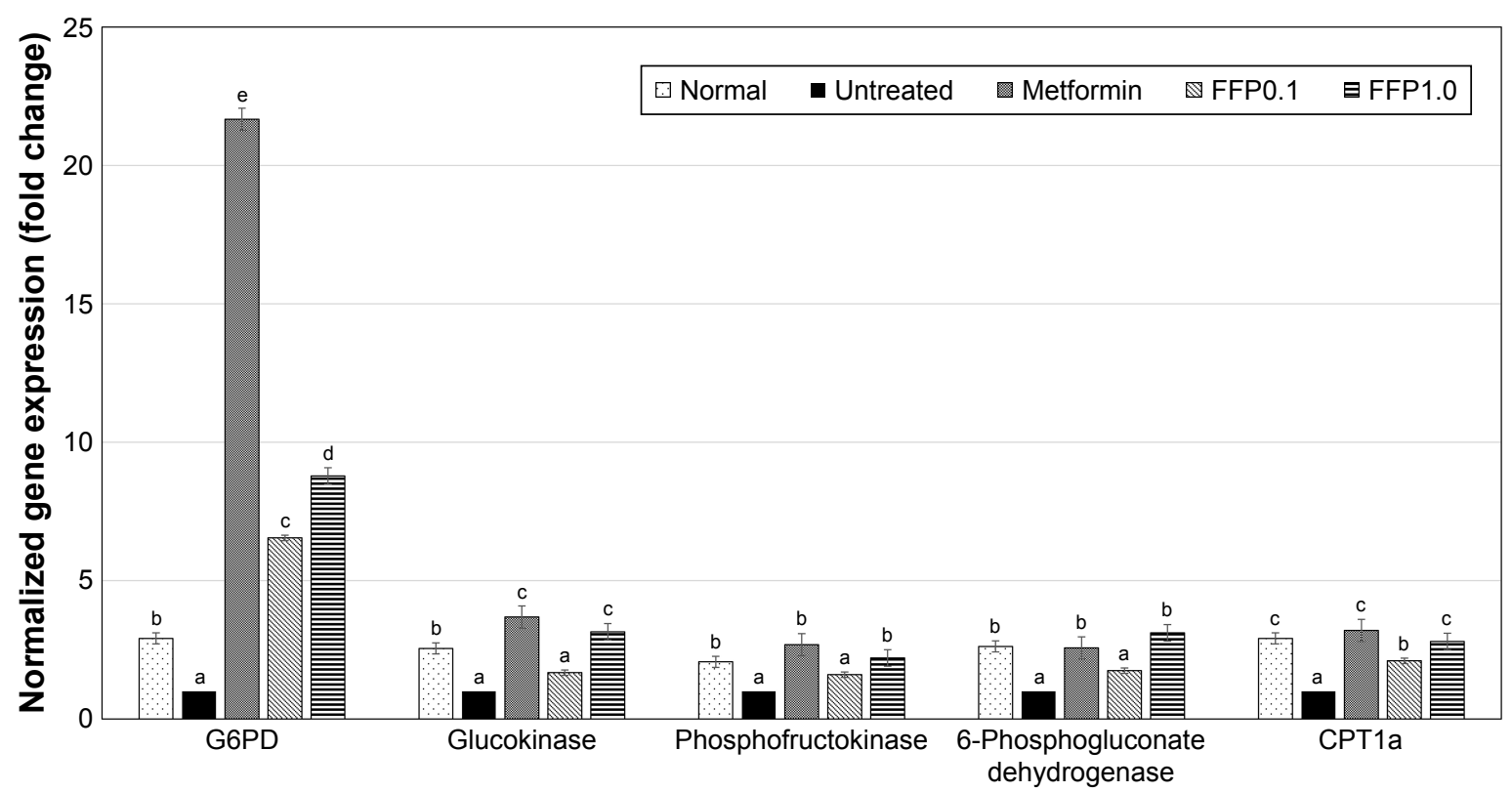

Figure 4 Differential expression of G6PD, glucokinase, phosphofructokinase, 6-phosphogluconate dehydrogenase, and CPT I a hepatic genes on normal, untreated, metformintreated, and FFP-supplemented diabetic mice. The expression of target genes ( \pm SEM) was normalized with $\beta$-actin, and the untreated diabetic group was used as control for comparison. Fold change $>2$ compared with the untreated group was considered significant. Different superscript letters indicate a significant difference compared with the untreated diabetic group, $p<0.05$.

Note: FFPO.I and FFPI.0 indicate 0.1 and $1.0 \mathrm{~g}$, respectively, of FFP per $\mathrm{kg}$ of body weight.

Abbreviation: FFP, fermented food paste.

through ameliorating the expression of genes related to glycolysis such as glucokinase, G6PD, phosphofructokinase, and 6-phosphogluconate dehydrogenase, ${ }^{21}$ which was also observed in the FFP diet-supplemented diabetic mice.

Adipokines are proteins secreted by adipocytes that are known to have direct or indirect regulation on insulin sensitivity. ${ }^{22}$ In this study, dysregulation on the production of adipokines such as leptin, adiponectin, IL- $1 \beta$, and TNF- $\alpha$ was observed in the untreated diabetic mice. Leptin, stimulated by hyperinsulinemia, is a hormone produced by adipocytes that promotes body fat accumulation. Over accumulation of leptin always promotes excessive food intake and reduces energy expenditure in obese subjects. ${ }^{15}$ On the other hand, adiponectin is a hormone produced by adipocytes that positively regulates energy expenditure and suppresses excessive food intake. ${ }^{15}$ IL-1 $\beta$ and TNF- $\alpha$ are proinflammatory cytokines that inhibit insulin secretion and induce apoptosis of $\beta$-cells via stimulating the generation of $\mathrm{NO}$ through the activation of inflammation. ${ }^{22}$ In this study, FFP diet supplement was able to upregulate the expression of adiponectin associated with reduced level of serum leptin, IL-1 $\beta$, and TNF- $\alpha$. In addition, reduced level of proinflammatory IL-1 $\beta$ was observed
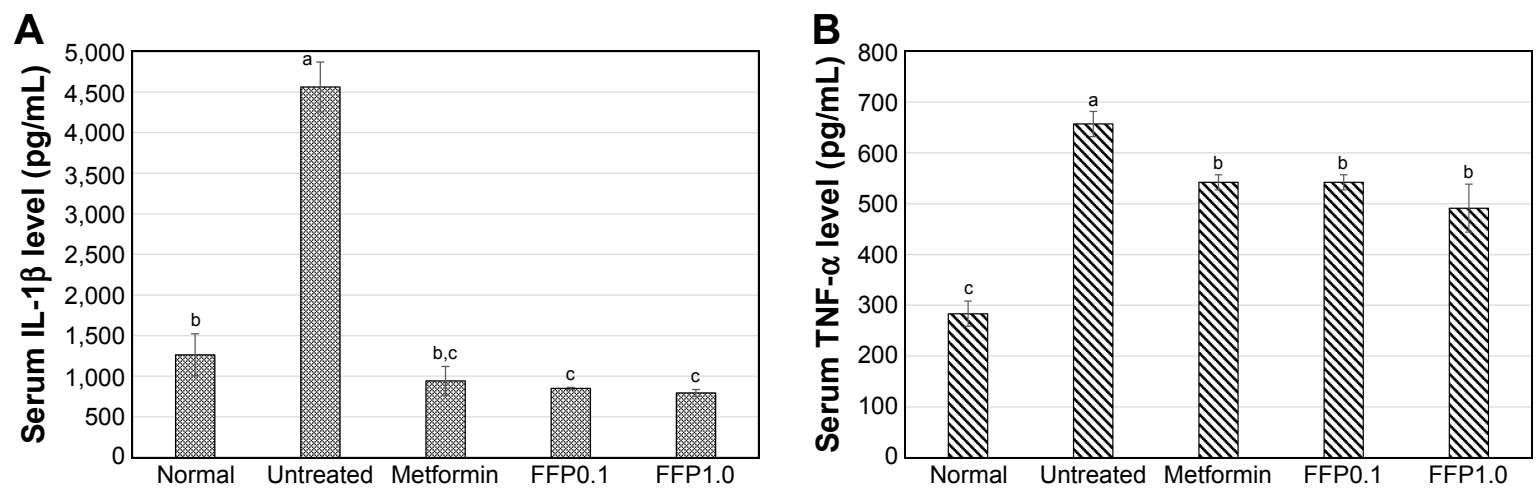

Figure 5 Serum (A) IL-I $\beta$ and (B) TNF- $\alpha$ of normal, untreated, metformin-treated, and FFP-supplemented diabetic mice. Different superscript letters indicate a significant difference compared with the untreated diabetic group, $p<0.05$.

Note: FFPO.I and FFPI.0 indicate 0.1 and $1.0 \mathrm{~g}$, respectively, of FFP per $\mathrm{kg}$ of body weight.

Abbreviations: IL-I $\beta$, interleukin-I $\beta$; TNF- $\alpha$, tumor necrosis factor- $\alpha$; FFP, fermented food paste. 


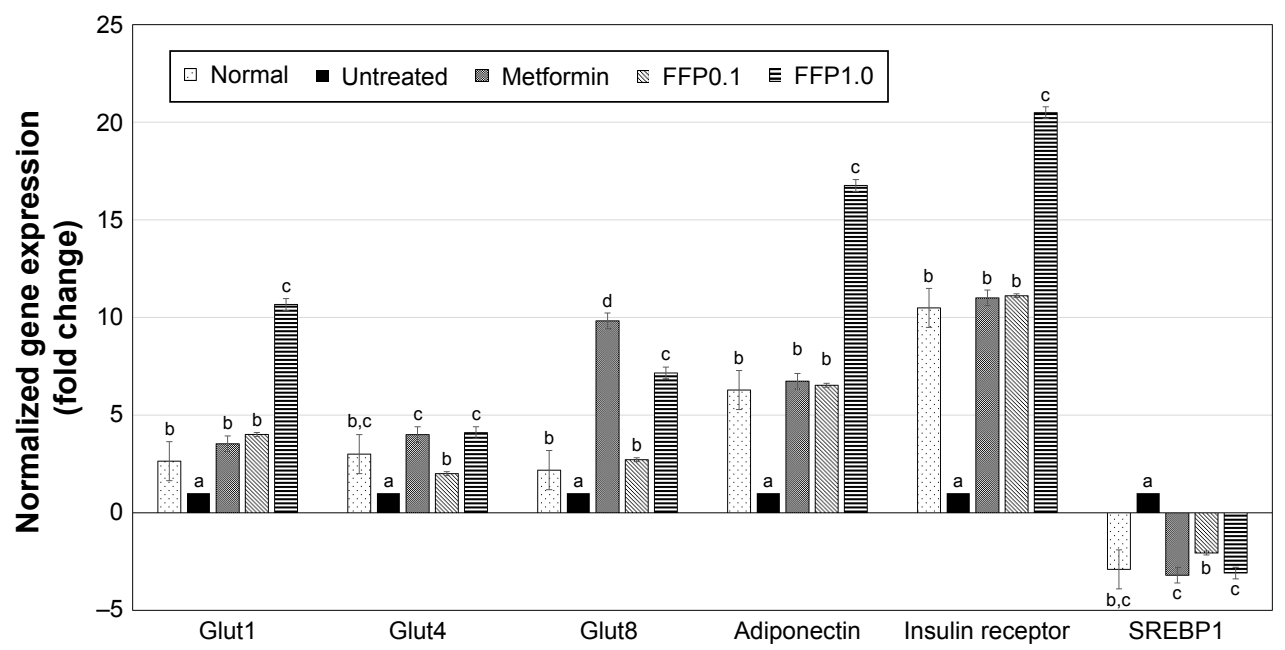

Figure 6 Differential expressions of Glutl, Glut4, Glut8, adiponectin, insulin receptor, and SREBPI genes in the fat pad of normal, untreated, metformin-treated, and FFPsupplemented diabetic mice. The expression of target genes $( \pm \mathrm{SEM})$ was normalized with $\beta$-actin and the untreated diabetic group was used as control for comparison. Fold change $>2$ compared with the untreated group was considered significant. Different superscript letters indicate a significant difference compared with the untreated diabetic group, $p<0.05$.

Note: FFPO.I and FFPI.0 indicate 0.1 and $1.0 \mathrm{~g}$, respectively, of FFP per kg of body weight.

Abbreviation: FFP, fermented food paste.

with the suppression of liver inflammation indicated by the lower level of liver NO and downregulation of expression of inflammatory markers NF-kB and iNOS. Reduced level of liver inflammation may contribute to the recovery of mild liver damage shown by lower level of serum liver enzyme profile in the FFP-supplemented diabetic mice. Moreover, suppression of leptin and improved insulin sensitivity may help to control the appetite of the diabetic mice as previous study has reported that leptin combined with insulin has reduced food intake and $\mathrm{BW}$ of rat. ${ }^{23}$ In addition, promotion of adiponectin expression and improvement of insulin sensitivity by FFP may also helped to reduce fat accumulation as indicated by lower levels of serum cholesterol and TG in the

A

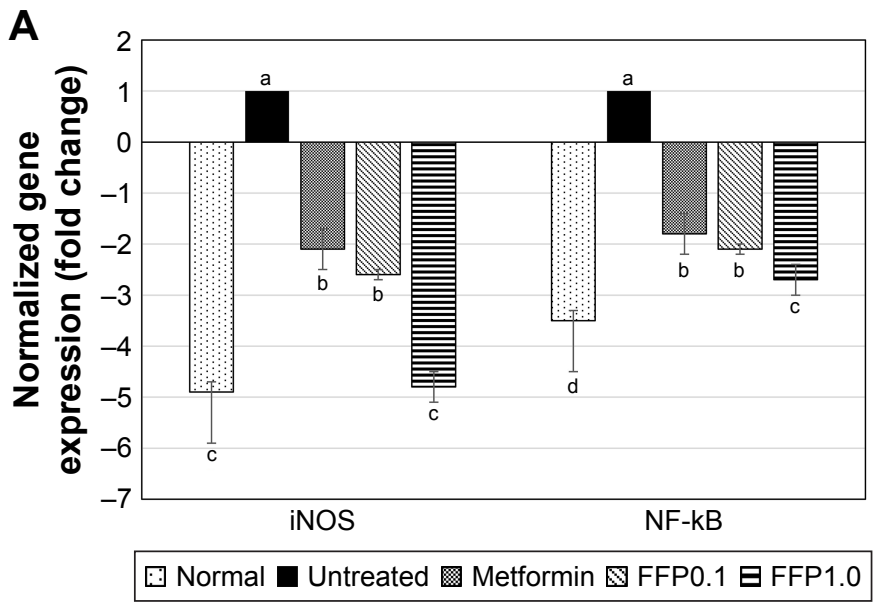

FFP-supplemented mice, which was similar to the previous reports that evaluated the role of adipokines. ${ }^{22,24}$ Besides improved insulin resistance, 6 weeks of FFP diet supplement was able to ameliorate the expression of CPTIa gene in liver, which was involved in fatty acid oxidation. ${ }^{25}$ On the contrary, it suppressed the expression of SREBP1 gene, which plays an important role in mediating accumulation of lipid and cholesterol homeostasis. ${ }^{24}$ Thus, improvement of serum cholesterol and TG level by FFP may also be contributed by the activation of lipid metabolism.

Foods including vegetables, mushrooms, fruits, herbs, and seaweed, which were used to produce FFP are known as natural sources of antioxidants, vitamins, and minerals. ${ }^{26}$

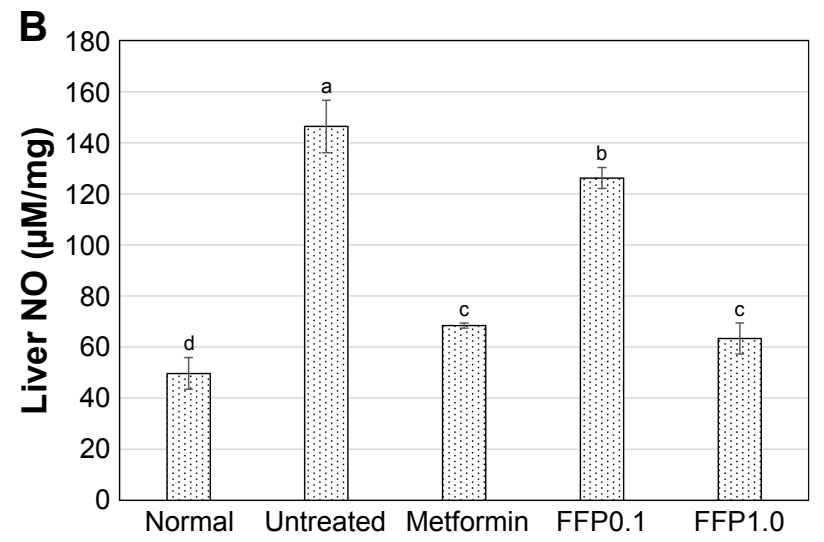

Figure 7 (A) Differential expression of NF-kB and iNOS genes in the liver of normal, untreated, metformin-treated, and FFP-supplemented diabetic mice. The expression of target genes $( \pm$ SEM) was normalized with $\beta$-actin, and the untreated diabetic group was used as control for comparison. Fold change $>2$ when compared with the untreated group was considered significant. (B) NO levels in livers of normal, untreated, metformin-treated, and FFP-supplemented diabetic mice. Different superscript letters indicate a significant difference compared with the untreated diabetic group, $p<0.05$.

Note: FFPO.I and FFPI.0 indicate 0.1 and $1.0 \mathrm{~g}$, respectively, of FFP per kg of body weight.

Abbreviations: NO, nitric oxide; FFP, fermented food paste; iNOS, inducible nitric oxide synthase; NF-kB, nuclear factor kappa B. 
Furthermore, fermentation by lactic acid bacteria was proposed as biological process that can enhance the biological activities of natural food. ${ }^{27}$ Previous study has reported that FFP contained oligosaccharides, essential amino acids, vitamins, and polyphenolic acids. ${ }^{10} \mathrm{~A}$ pilot clinical trial has shown that supplementation with amino acid helped to reduce the plasma glucose and improved insulin sensitivity of type 2 diabetes patients. ${ }^{25}$ Moreover, amino acid arginine was also found to improve glucose tolerance in obese mice. ${ }^{28}$ On the other hand, polyphenolic acids particularly caffeoylquinic acid, which is the most abundant polyphenol in FFP, ${ }^{12}$ were reported with antihyperglycemic ${ }^{29}$ and anti-inflammatory ${ }^{30}$ effects. Oligosaccharides in various types of food including mushrooms were also reported with antidiabetic effect. ${ }^{31}$ Thus, the antihyperglycemic and anti-inflammatory effects of FFP may be contributed by not only the polyphenolic acids but also essential amino acids, oligosaccharides, and even other bioactive metabolites that are present in the sample.

It can be concluded that FFP possessed antihyperglycemic and anti-inflammatory effects toward the HFD-streptozotocinchallenged mice. This antidiabetic effect was mainly contributed by improved insulin sensitivity, glucose metabolism, glycogen metabolism, and inhibition of lipid deposition. The observed activities can be contributed by the presence of essential amino acids, vitamins, and polyphenolic acids in the FFP as reported in the previous study. ${ }^{10,12}$

\section{Acknowledgment}

Dr Kamariah Long would like to thank Elken Global Sdn Bhd for awarding the research grant.

\section{Author contributions}

All authors contributed toward data analysis, drafting and critically revising the paper, gave final approval of the version to be published, and agree to be accountable for all aspects of the work.

\section{Disclosure}

Noraisyah Zulkawi and Kam Heng Ng are from Elken Global Sdn. Bhd, Malaysia, which funded this study. The authors report no other conflicts of interest in this work.

\section{References}

1. Hu FB. Globalization of diabetes. The role of diet, lifestyle, and genes. Diabetes Care. 2011;34:1249-1257.

2. Bhandari U, Chaudhari HS, Khanna G, Najmi AK. Antidiabetic effects of Embelia ribes extract in high fat diet and low dose streptozotocininduced type 2 diabetic rats. Front Life Sci. 2013;7:186-196.

3. Steyn NP, Mann J, Bennett PH, et al. Diet nutrition and the prevention of type 2 diabetes. Public Health Nutr. 2004;7:147-165.
4. Kwon DY, Daily JW, Kim HJ, Park S. Antidiabetic effects of fermented soybean products on type 2 diabetes. Nutr Res. 2010;30:1-13.

5. Adeyemo SM, Onillude AA. Enzymatic reduction of anti-nutritional factors in fermenting soybeans by Lactobacillus plantarum isolates from fermenting cereals. NIFOJ. 2013;31:84-90.

6. Ankolekar C, Pinto M, Greene D, Shetty K. Phenolic bioactive modulation by Lactobacillus acidophilus mediated fermentation of cherry extracts for anti-diabetic functionality, Helicobacter pylori inhibition and probiotic Bifidobacterium longum stimulation. Food Biotechnol. 2011; 25:305-335.

7. Telang AM, Joshi VS, Sutar N, Thorat BN. Enhancement of biological properties of soymilk by fermentation. Food Biotechnol. 2010;24: 375-387.

8. Kuwaki S, Nakajima N, Tanaka H, Ishihara K. Plant-based paste fermented by lactic acid bacteria and yeast: functional analysis and possibility of application to functional foods. Biochem Insights. 2012;5: $21-29$.

9. Honda K, Moto M, Uchida N, He F, Hashizume N. Anti-diabetic effects of lactic acid bacteria in normal and type 2 diabetic mice. J Clin Biochem Nutr. 2012;51:96-101.

10. Zulkawi $\mathrm{N}, \mathrm{Ng} \mathrm{KH}$, Zamberi R, et al. In vitro characterization and in vivo toxicity, antioxidant and immunomouldatory effect of fermented foods; Xeniji ${ }^{\mathrm{TM}}$. BMC Complement Altern Med. 2017;17:344.

11. Shimada T, Motonaga C, Matsuura S, et al. Effects of a fermented vegetable product on fat deposition and bone metabolism in ovariectomized rats. J Nutr Sci Vitaminol (Tokyo). 2004;50:422-425.

12. Zulkawi N, Ng KH, Zamberi R, et al. The in vivo hepato-recovery effects of the polyphenolic rich fermented food Xeniji on ethanol-induced liver damage. RSC Adv. 2017;7:38287-38299.

13. Tamang JP, Shin DH, Jung SJ, Chae SW. Functional properties of microorganisms in fermented foods. Front Microbiol. 2016;7:578.

14. Beh BK, Mohamad NE, Yeap SK, et al. Anti-obesity and anti-inflammatory effects of synthetic acetic acid vinegar and Nipa vinegar on high fatdiet-induced obese mice. Sci Rep. 2017;7:6664.

15. Tahara A, Matsuyama-Yokono A, Shibasaki M. Effects of antidiabetic drugs in high-fat diet and streptozotocin-nicotinamide-induced type 2 diabetic mice. Eur J Pharmacol. 2011;655:108-116.

16. Nishidai S, Nakamura Y, Torikai K, et al. Kurosu, a traditional vinegar produced from unpolished rice, suppresses lipid peroxidation in vitro and in mouse skin. Biosci Biotechnol Biochem. 2000;64:1909-1914.

17. Scheen AJ. Pathophysiology of type 2 diabetes. Acta Clin Belg. 2003;58: 335-341.

18. Camacho S, Michlig S, de Senarclens-Bezencon C, et al. Anti-obesity and anti-hyperglycemic effects of cinnamaldehyde via altered ghrelin secretion and functional impact on food intake and gastric emptying. Sci Rep. 2015;5:7919.

19. Lu F, Cai Q, Zafar MI, et al. 4-Hydroxyisoleucine improves hepatic insulin resistance by restoring glycogen synthesis in vitro. Int J Clin Exp Med. 2015;8:8626-8633.

20. Kotani K, Peroni OD, Minokoshi Y, Boss O, Kahn BB. GLUT4 glucose transporter deficiency increases hepatic lipid production and peripheral lipid utilization. J Clin Invest. 2004;114:1666-1175.

21. Miyanaga O, Nagano M, Cottam GL. Effect of insulin on liver pyruvate kinase in vivo and in vitro. J Biol Chem. 1982;257:10617-10623.

22. Dunmore SJ, Brown JE. The role of adipokines in $\beta$-cell failure of type 2 diabetes. $J$ Endocrinol. 2013;216:T37-T45.

23. Coll AP, Farooqi IS, O'Rahilly S. The hormonal control of food intake. Cell. 2002;129:251-262.

24. Ahn TG, Yang G, Lee HM, et al. Molecular mechanisms underlying the anti-obesity potential of prunetin, an O-methylated isoflavone. Biochem Pharmacol. 2013;85:1525-1533.

25. Bechmann LP, Hannivoort RA, Gerken G, Hotamisligil GS, Trauner M, Canbay A. The interaction of hepatic lipid and glucose metabolism in liver diseases. J Hepatol. 2012;56:952-964.

26. Xu DP, Li Y, Meng X, et al. Natural antioxidants in foods and medicinal plants: extraction, assessment and resources. Int J Mol Sci. 2017;18: pii:E96. 
27. Nguyen NK, Dong NT, Nguyen HT, Le PH. Lactic acid bacteria: promising supplements for enhancing the biological activities of kombucha. Springerplus. 2015;4:91.

28. Clemmensen C, Smajilovic S, Smith EP, et al. Oral L-arginine stimulates GLP-1 secretion to improve glucose tolerance in male mice. Endocrinology. 2013;154:3978-3983.

29. Wu C, Zhang X, Zhang X, et al. The caffeoylquinic acid-rich Pandanus tectorius fruit extract increases insulin sensitivity and regulates hepatic glucose and lipid metabolism in diabetic $\mathrm{db} / \mathrm{db}$ mice. J Nutr Biochem. 2014;25:412-419.
30. Liu SL, Penag BJ, Zhong YL, Liu YL, Song Z, Wang Z. Effect of 5-caffeoylquinic acid on the NF-kB signalling pathway, peroxisome proliferator-activated receptor gamma 2 , and macrophage infiltration in high-fat diet-fed Sprague-Dawley rat adipose tissue. Food Funct. 2015;6: 2779-2786.

31. Friedman M. Mushroom polysaccharides: chemistry and antiobesity, antidiabetes, anticancer, and antibiotic properties in cells, rodents, and humans. Foods. 2016;5:pii:E80.

\section{Publish your work in this journal}

Drug Design, Development and Therapy is an international, peerreviewed open-access journal that spans the spectrum of drug design and development through to clinical applications. Clinical outcomes, patient safety, and programs for the development and effective, safe, and sustained use of medicines are the features of the journal, which has also been accepted for indexing on PubMed Central. The manuscript management system is completely online and includes a very quick and fair peer-review system, which is all easy to use. Visit http://www.dovepress.com/testimonials.php to read real quotes from published authors.

Submit your manuscript here: http://www.dovepress.com/drug-design-development-and-therapy-journal 